\title{
Lead acetate- induced neurodegenerative changes in the dorsolateral prefrontal cortex of mice: the role of Vitexin
}

\author{
Nathaniel Ohiemi Amedu ${ }^{1,2}{ }^{10}$, Gabriel Olaiya Omotoso ${ }^{1}$ \\ 'Department of Anatomy, Faculty of Basic Medical Sciences, College of Health Sciences, University of Ilorin, P.M.B. 1515, Ilorin, Nigeria; ${ }^{2}$ Department of \\ Anatomy, Faculty of Basic Medical Sciences, College of Health Sciences, Kogi State University, P.M.B. 1008, Anyigba, Nigeria.
}

\begin{abstract}
This study was aimed at investigating the neuroprotective effect of Vitexin against lead $(\mathrm{Pb})$ induced neurodegenerative changes in the dorsolateral prefrontal cortex (DLPFC) and working memory in mice. Thirty-two adolescent male albino mice were divided into four groups ( $\mathrm{n}=8$ ). Control group received $0.2 \mathrm{~mL}$ of normal saline; Pb group received $100 \mathrm{mg} / \mathrm{kg}$ of Pb acetate for 14 days, Vitexin group received $1 \mathrm{mg} / \mathrm{kg}$ of Vitexin for 14 days, and $\mathrm{Pb}+$ Vitexin group received $100 \mathrm{mg} / \mathrm{kg}$ of Pb acetate and $1 \mathrm{mgkg}$ of Vitexin for 14 days. Barnes maze test and novel object recognition test were done to ascertain working memory. Histoarchitectural assessment of DLPFC was done with haematoxylin and eosin (HEEE), cresyl fast violet and congo red stains. Furthermore, cell count and other morphometric measurements were done. There was significant decline in working memory in the Pb group, but a combination of $\mathrm{Pb}+\mathrm{Vitexin}$ improved the working memory. Vitexin significantly reduced neuronal death and chromatolysis caused by $\mathrm{Pb}$. Amyloid aggregation was not observed in any of the groups. This study has shown that concurrent administration of Vitexin and $\mathrm{Pb}$ will significantly reduce neurodegeneration and improve working memory. However, Pb treatment or $\mathrm{Pb}+\mathrm{Vitexin}$ treatment does not have any effect on intercellular distance, neuronal length and the cross-sectional area of neurons in layer III of DLPFC.
\end{abstract}

Keywords: Vitexin, lead acetate, neurodegeneration, prefrontal cortex, working memory

\section{Introduction}

The gradual loss of structure or function of neurons, that also involves neuronal death often result in diseases or conditions that affect mental functioning and proper movement [1]. Environmental factors are part of the contributors to the pathogenesis of neurodegenerative diseases [2]. Lead $(\mathrm{Pb})$ is one of the well-known environmental toxins that cause neurodegeneration, affect neurodevelopment and mental health [3-6].

$\mathrm{Pb}$ is a heavy metal that is widely used in various forms despite well-documented reports of its toxic effects [7]. Exposure to $\mathrm{Pb}$, even in low doses, results in various adverse consequences, particularly in the brain [8]. $\mathrm{Pb}$, as a neurotoxicant, crosses the blood-brain barrier to cause oxidative stress [9], morphologic damage, neurodegeneration and cognitive impairment in the brain, particularly that of developing brain [10-13]. The prefrontal cortex (PFC), which accounts for one-

Received: Sep 26, 2019 Accepted: Jan 23, 2020

Corresponding author: Nathaniel Ohiemi Amedu

Department of Anatomy, Faculty of Basic Medical Sciences, College of Health

Sciences, Kogi State University, P.M.B 1008, Anyigba.

E-mail: amedunath11@gmail.com

This article is available from: $h$ ttps://eaht.org/ third of the human cerebral cortex, is responsible for working memory, higher reasoning, decision making and many other executive functions $[14,15]$. There are evidences that intrinsic connections of the dorsolateral PFC (DLPFC) (Brodmann areas 9 \& 46) make more connections with other parts of PFC which are relevant to cognitive processing [16-18].

Since neurotoxicity by $\mathrm{Pb}$ was confirmed as one of the causative agents of neurodegeneration, emerging evidence suggests that dietary phytochemicals have potentials to chelate its effects. In this sense, flavonoid may act on several therapeutic targets to prevent or reduce the events involved in neurodegeneration caused by $\mathrm{Pb}$ neurotoxicity,

Flavonoids have been proposed to limit neurodegeneration in diverse neurological diseases, including cognitive impairments $[19,20]$. According to emerging evidence, dietary flavonoids and their metabolites cross the blood-brain barrier and exert multiple neuropharmacological actions which include modulating the innate architecture of the brain to impact cognitive function and have a neuroprotective effect [19]. Crucial factors that are involved in inducing synaptic plasticity, suppression of neuroinflammatory processes, promotion of cerebrovascular perfusion, and activation of adaptive cellular 
stress response to protect against oxidative stressors by flavonoids are regulation of neuronal signalling cascades and transcription factors $[19,20]$. Vitexin is one of flavonoids that is rapidly gaining the attention of researchers because of is various potentials.

Vitexin is a flavonoid that is extracted from various plants including pearl millet, hawthorn, pigeon pea, mung bean, mosses, Passiflora, bamboo, mimosa, wheat leaves, and chaste berry [21]. Its effects are reported in pharmacological roles range from anti-oxidative anti tumour, anti-viral, anti-inflammatory, anti-bacterial, antihypertensive, antinociceptive, antispasmodic, anti-diabetic, antidepressant, neuroprotective and cognitive improving functions [22-28]. The contribution of Vitexin to neuroprotection is through counteracting the targets that induce neurodegeneration, such as redox imbalance, neuroinflammation and abnormal protein aggregation, which then lead to a reduction of cognitive or motor impairment [24].

Although the preventive effects of Vitexin on neurodegeneration could be considered mostly substantiated, the positive neuroprotective activity after acute $\mathrm{Pb}$ administration still deserves more research. Hence, the aim of the study was to investigate the neuroprotective effect of Vitexin against $\mathrm{Pb}$ induced neurodegenerative changes in the DLPFC and working memory impairment in mice.

\section{Materials and methods}

\section{Treatment solution}

Vitexin extract and $\mathrm{Pb}$ acetate were purchased from SigmaAldrich (St Louis, MO, USA). Phosphate buffered saline was freshly prepared, while other materials were purchased locally. $\mathrm{Pb}$ acetate solution was prepared by dissolving $500 \mathrm{mg}$ of $\mathrm{Pb}$ in $1 \mathrm{~mL}$ water. Vitexin solution was freshly prepared each morning of administration before use. Vitexin was dissolved in normal saline $(\mathrm{NaCl}, 0.9 \%)$. $\mathrm{Pb}$ treatments on mice were done using oral gavage, while all Vitexin treatment was via intraperitoneal injection (IP).

\section{Animals}

Thirty-two adolescent male albino mice (weight: 17-18g) were procured from the Temidale animal husbandry centre, Ogbomosho, Nigeria. The animals were acclimatized for 14 days on a $12 \mathrm{~h}$ of light/dark cycle at the animal holdings of Central Research Lab, of the University of Ilorin, Nigeria, before administration. The animals were maintained under the National Institutes of Health guide for the care and use of laboratory animals (NIH Publications, 8th edition). The Universi- ty of Ilorin Ethical and Review Committee approved the experimental protocols used in the study (number: UERC/ ASN/2018/1257).

\section{Animal grouping and administration}

The animals were randomly divided into four groups of eight animals. Group A which was also the control group was administered $0.2 \mathrm{~mL}$ normal saline for 14 days via oral gavage; Group $\mathrm{B}$ ( $\mathrm{Pb}$ group) received oral gavage of $\mathrm{Pb}$ acetate $100 \mathrm{mg} /$ $\mathrm{kg}_{\mathrm{bw}}$-d for 14 days; Group C (Vitexin group) received intraperitoneal injection of Vitexin $1 \mathrm{mg} / \mathrm{kg}_{\mathrm{bw}}-\mathrm{d}$ for 14 days; Group D $(\mathrm{Pb}+$ Vitexin group) received concurrent administration of 100 $\mathrm{mg} / \mathrm{kg}_{\mathrm{bw}}-\mathrm{d}$ of $\mathrm{Pb}+1 \mathrm{mg} / \mathrm{kg}_{\mathrm{bw}}-\mathrm{d}$ Vitexin for 14 days.

\section{Barmes maze test}

This test for spatial learning memory was done between 21st to 25th day after the end of administration according to the modified methods in literature [29]. In this test, a circular table with 15 holes around the circumference, was placed in a lighted room. Fourteen holes of them lead to an open drop to the floor, but a single hole leads to a dark box that the animal can hide. In initial trials, the animals were placed in the centre of the table and were led to the dark box. In subsequent trials, the animals were placed in the centre of the table and were to find the dark box on their own. The test was recorded using a video camera attached to a computer. The record of the number of incorrect holes visited before the correct hole was also taken. The time it took for the animals to find the correct hole was recorded.

\section{Novel object recognition (NOR) test}

This test was carried out between 26th to 30th day after administration according to the method described in previous literature [30]. The first two days of this test was for habituation; the third was the trial while the fourth day was the test proper. At the end of this test, the percentage preference for the new object was calculated,

\section{Preparation of brain sample}

At the end of the last neurobehavioral test, the animals were anaesthetized with an intraperitoneal injection of ketamine (90 mg/kg). The mice were transcardially perfused with $4 \%$ paraformaldehyde (PFA) in phosphate buffer saline (PBS) solution. Excised PFC tissues were postfixed in 4\% PFA for 24 hours before transferring into a cold $20 \%$ sucrose solution. Tissue was processed as paraffin wax embedded blocks, while haematoxylin and eosin (H\&E), cresyl fast violet (CFV) and congo red staining procedures, were carried out [31]. 


\section{Photomicrography and cell count}

Stained sections were viewed under a light binocular microscope (Olympus, NJ, USA) attached to an amscope camera (MD500, CA, USA). Six visual fields of CFV stain of the DLPFC were photographed in each section and were used for cell counting as well as other morphometric analysis with the aid of Image J 1.52r software (National Institute of Health, USA). The DLPFC was identified [32].

\section{Statistical analysis}

All statistical analyses and graph fitting were performed using Graph Pad Prism version 5.0 for Windows. The significance of difference was determined using one-way ANOVA followed by Tukey's posthoc test for all parameters. All data were expressed as the mean \pm standard error of the mean
(SEM), with $\mathrm{n}$ representing the number of animals used in each experiment. Statistical significance was defined at the level of $\mathrm{p}<0.05$.

\section{Results}

\section{Effect of Vitexin and lead $(\mathrm{Pb})$ acetate on learning}

The result from the Barnes maze test (Figure 1) shows no statistically significant difference $(\mathrm{p}>0.05)$ when the $\mathrm{Pb}$ group was compared with the other groups within the first three days of learning acquisition. Starting from the fourth day (retention day), the time it took animals to locate the dark box in control, vitexin, and $\mathrm{Pb}+$ Vitexin groups became significantly shorter when compared with the $\mathrm{Pb}$ group $(\mathrm{p}<0.001$; $\mathrm{p}<0.001$ and $\mathrm{p}$ $<0.05$ respectively). Similarly, the number of incorrect holes
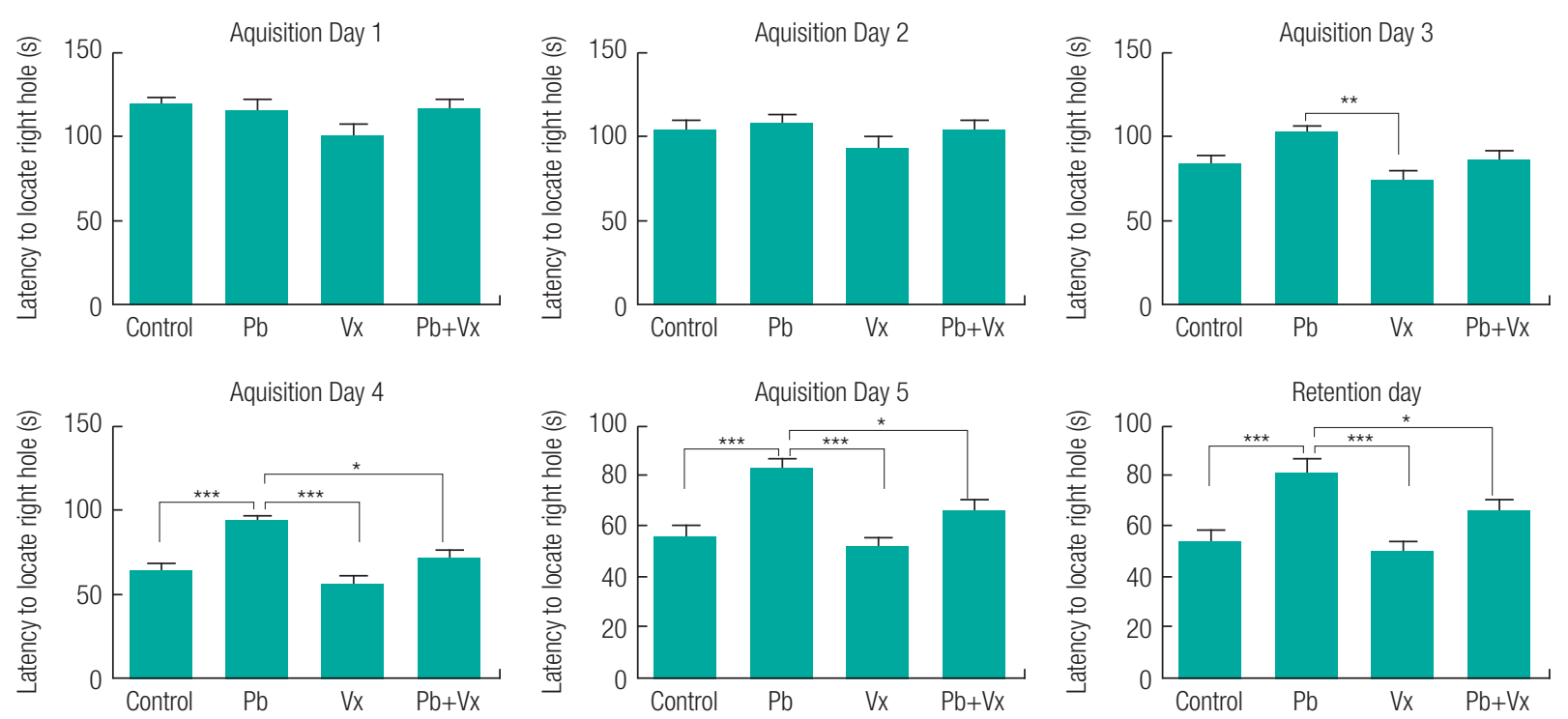

Figure 1. Barnes maze test. Data express as mean $\pm S E M(n=8)$; Control=control group; $P b=L e a d$ acetate treated group; $V x=V i t e x i n$ treated group; and $\mathrm{Pb}+\mathrm{Vx}=$ Lead acetate+Vitexin treated group. ${ }^{*} \mathrm{p}<0.05 ;{ }^{* *} \mathrm{p}<0.01 ;{ }^{* * *} \mathrm{p}<0.001$

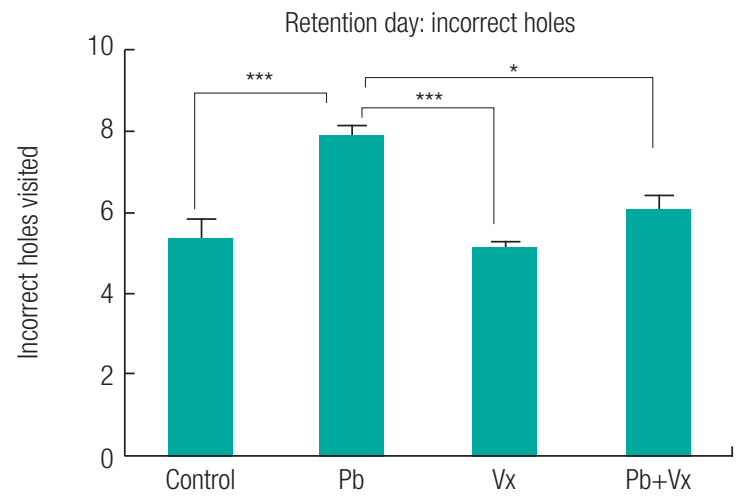

Figure 2. Number of incorrect holes visited on retention day of Barnes maze test. Data express as mean \pm SEM $(n=8)$; Control=control group; $\mathrm{Pb}=$ Lead acetate treated group; $\mathrm{V} x=$ Vitexin treated group; and $\mathrm{Pb}+\mathrm{Vx}=$ Lead acetate and Vitexin treated group. ${ }^{*} p<0.05 ;{ }^{* *} p<0.01 ;{ }^{* * *} p<0.001$.

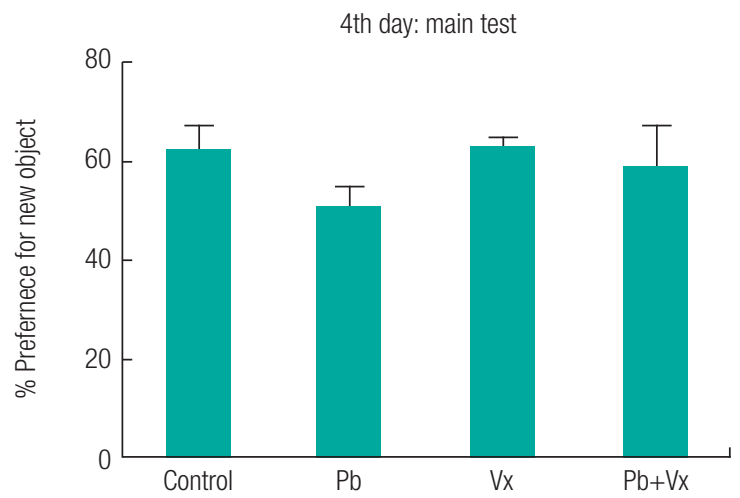

Figure 3. Novel object recognition test. Data express as mean \pm SEM $(\mathrm{n}=8)$; Control=control group; $\mathrm{Pb}=$ Lead acetate treated group; $\mathrm{Vx}=$ Vitexin treated group; and $\mathrm{Pb}+\mathrm{V} x=$ Lead acetate and Vitexin treated group. ${ }^{*} \mathrm{p}<0.05 ;{ }^{* \star} \mathrm{p}<0.01 ;{ }^{* \star *} \mathrm{p}<0.001$. 

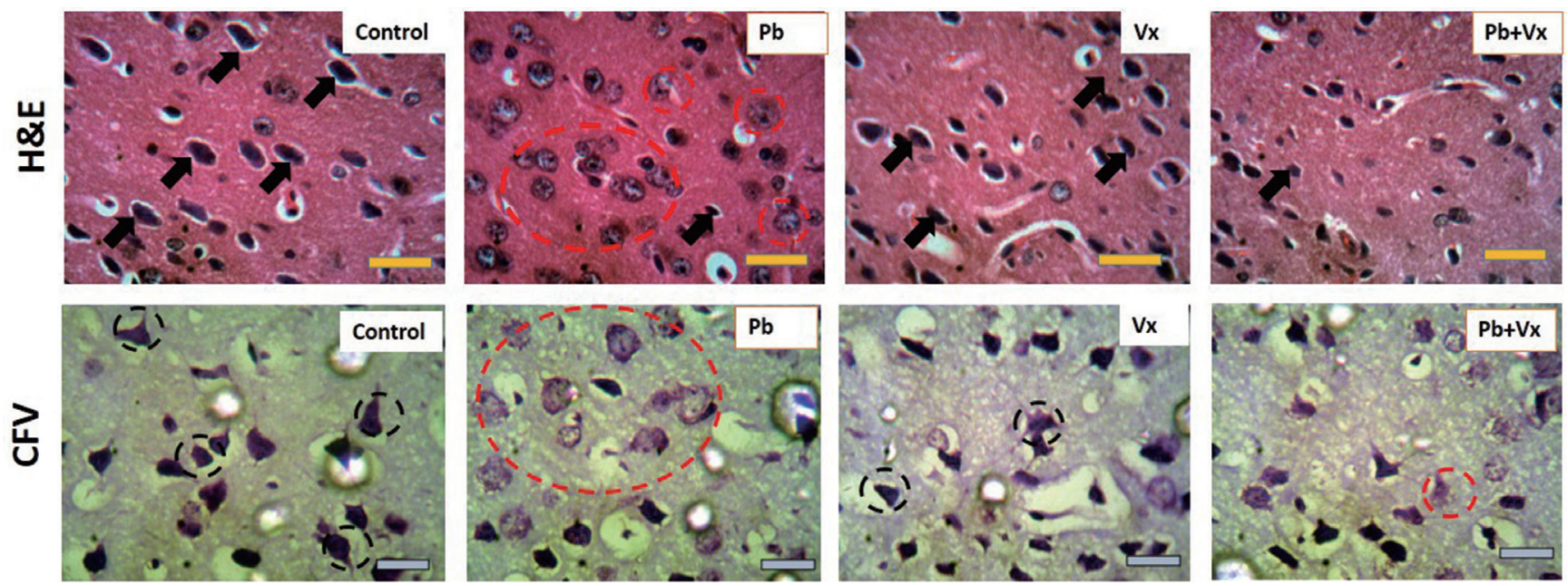

Figure 4. Representative photomicrograph of haematoxylin and eosin (H\&E) stain as well as cresyl fast violet (CFV) stain of the dorsolateral prefrontal cortex (DLPFC) in mice. Control= control group; $\mathrm{Pb}=$ Lead acetate treated group; $\mathrm{Vx}=$ Vitexin treated group; and $\mathrm{Pb}+\mathrm{V} \mathrm{x}=$ Lead acetate + Vitexin treated group. Black arrows= pyramidal neurons; Dotted red circles= degenerative changes; Black dotted circle= intensely stained Nissl substances, Scale bar= $45 \mu \mathrm{m}$.
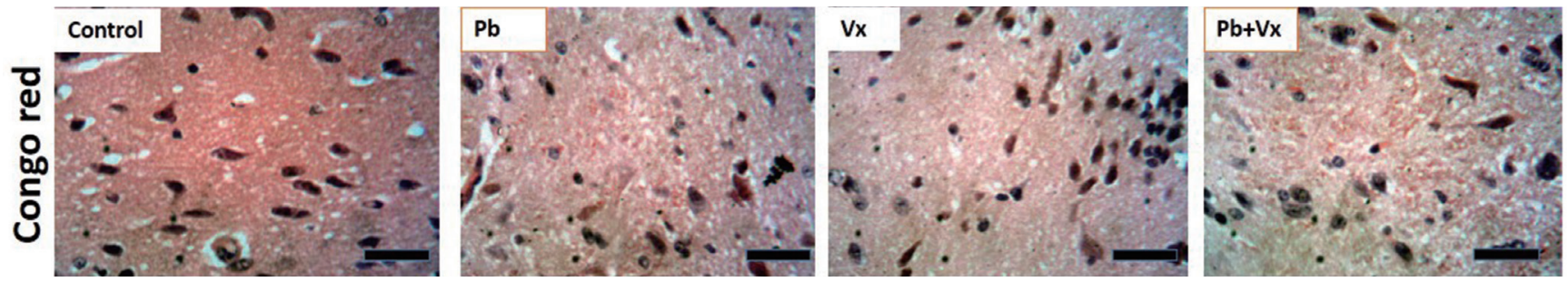

Figure 5. Representative photomicrograph of congo red stain of the dorsolateral prefrontal cortex (DLPFC) in mice. Control= control group; $\mathrm{Pb}=\mathrm{Lead}$ acetate treated group; $\mathrm{Vx}=$ Vitexin treated group; and $\mathrm{Pb}+\mathrm{Vx}=$ Lead acetate and Vitexin treated group. Scale bar $=45 \mu \mathrm{m}$.

visited by the animals before finding the dark box on the retention day (Figure 2) was significantly reduced in the control, Vitexin, and $\mathrm{Pb}+$ Vitexin groups $(\mathrm{p}<0.001 ; \mathrm{p}<0.001$ and $\mathrm{p}<0.05$ respectively) when comparisons were made with $\mathrm{Pb}$ group. Furthermore, in the NOR test, the percentage preference of the animals (Figure 3) to a new object, was generally higher in control, Vitexin, and $\mathrm{Pb}+\mathrm{Vitexin}$ groups than the $\mathrm{Pb}$ group. However, the difference in percentage preference of the animals to a new object was not statistically significant.

\section{Histoarchitectural observation}

The representative photomicrograph of H\&E-stained sections of mice DLPFC at higher magnification showed the control group with normal cytoarchitecture that was characterized by large pyramidal neurons (black arrows in Figure 4) with small perineural spaces. The $\mathrm{Pb}$ group showed degenerative changes that were characterized by numerous pyknotic pyramidal neurons that appear with fragmented cytoplasm and condensed nuclei within the soma (dotted red circles in Figure 4). Vitexin group present similar cytoarchitecture to the control group. The $\mathrm{Pb}+$ Vitexin group showed recovery in the

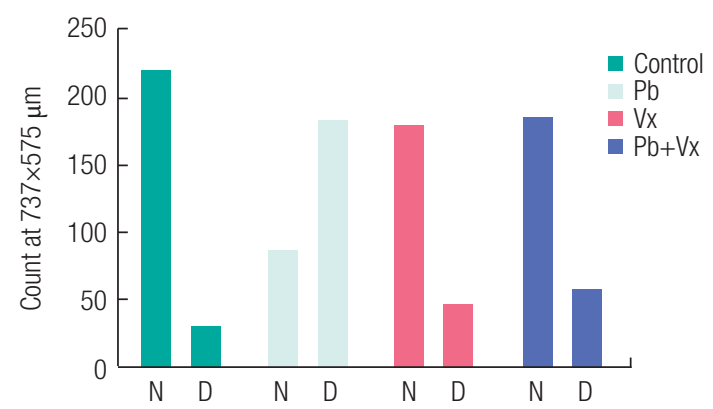

Figure 6. Number of normal neuron to degenerating neuron in Layer III of dorsolateral prefrontal cortex (DLPFC) in mice. Control= control group; $\mathrm{Pb}=$ Lead acetate treated group; $\mathrm{V} x=$ Vitexin treated group; and $\mathrm{Pb}+\mathrm{V} \mathrm{x}=$ Lead acetate and Vitexin treated group.

histoarchitecture when compared to the degenerative changes that were observed in the $\mathrm{Pb}$ group.

The representative photomicrograph of CFV stained sections of mice DLPFC showed the control and Vitexin groups stain intensely for Nissl (black dotted circle in Figure 4) with very few chromatolytic cells. However, in Pb group, numerous cells undergo chromatolysis (red dotted circle in Figure 4). In the 
Table 1. Layer II-III thickness expressed $(\mu \mathrm{m})$

\begin{tabular}{lcccc}
\hline Layers & control & $\mathrm{Pb}$ & $\mathrm{Vx}$ & $\mathrm{Pb}+\mathrm{Vx}$ \\
\hline$\|$ IIII & $360.1 \pm 27$ & $128.2 \pm 22^{\mathrm{a}}$ & $276.3 \pm 10^{\mathrm{a}, \mathrm{b}}$ & $221.5 \pm 6^{\mathrm{a}, \mathrm{b}, \mathrm{c}}$ \\
\hline
\end{tabular}

Control = control group; $\mathrm{Pb}=$ Lead acetate treated group; $\mathrm{Vx}=$ Vitexin treated group; and $\mathrm{Pb}+\mathrm{Vx}=$ Lead acetate and Vitexin treated group. astatistically significant with control; bstatistically significant with $\mathrm{Pb}$; cstatistically significant with Vitexin.

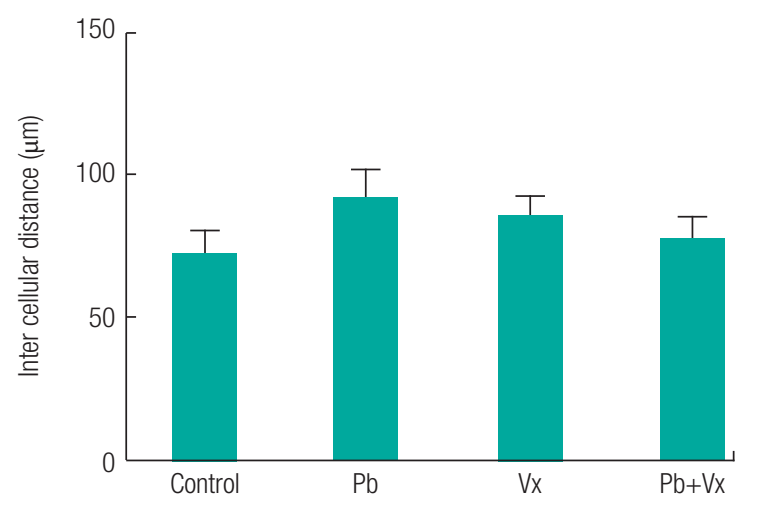

Figure 7. Intercellular distance in layer III of dorsolateral prefrontal cortex (DLPFC) in mice. Control=control group; $\mathrm{Pb}=$ Lead acetate treated group; $\mathrm{V} x=$ Vitexin treated group; and $\mathrm{Pb}+\mathrm{V} \mathrm{x}=$ Lead acetate and Vitexin treated group.

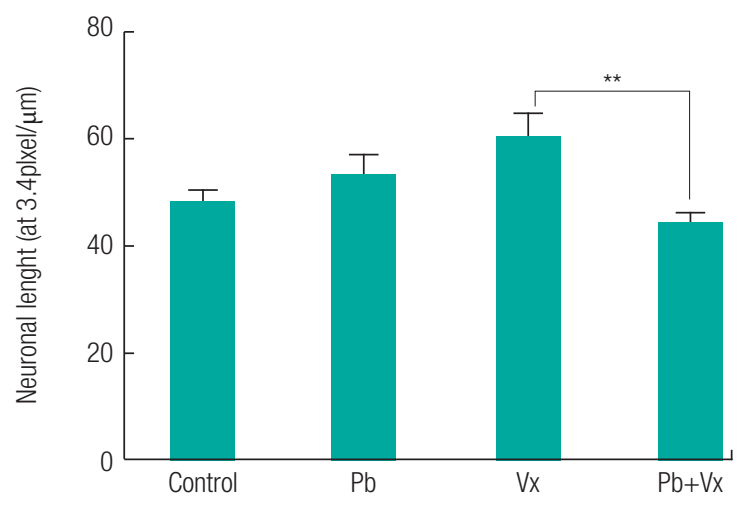

Figure 8. Neuronal length in layer III of dorsolateral prefrontal cortex (DLPFC) in mice. Control=control group; $\mathrm{Pb}=$ Lead acetate treated group; $\mathrm{Vx}=$ Vitexin treated group; and $\mathrm{Pb}+\mathrm{Vx}=\mathrm{Lead}$ acetate and Vitexin treated group.

$\mathrm{Pb}+$ Vitexin group, there were fewer chromatolytic cells when compared to the observation in $\mathrm{Pb}$ group. Furthermore, there appear to be no amyloid aggregation in any of the groups when the sections were stained with congo red (Figure 5).

In Figure 6, it was observed that there were more degenerating neurons in $\mathrm{Pb}$ group than healthy neurons when the count was analyzed $(p<0.001)$. The result was contrary to the observation in others where healthy neurons were significantly higher than degenerating neurons. In control, Vitexin, and $\mathrm{Pb}+$ Vitexin groups, the $\mathrm{p}$ values between normal and degenerating neuron count were all $<0.001$.

Intercellular distance between healthy neurons in each of the groups were not statistically significant $(p>0.05)$ when

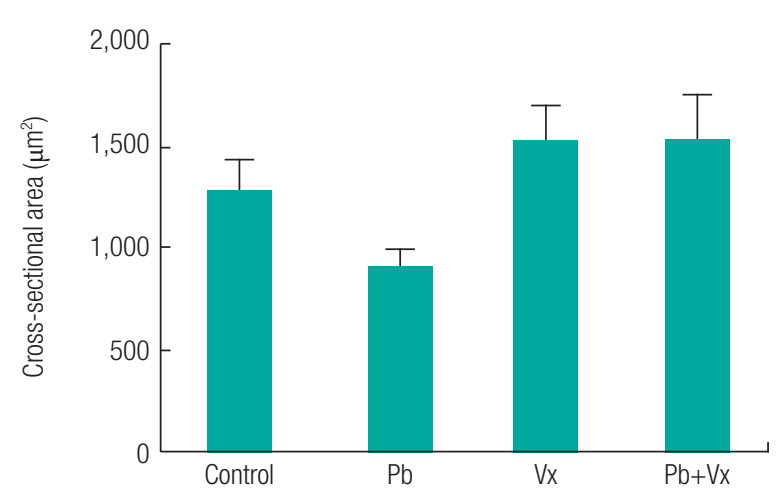

Figure 9. Cross sectional area of neurons in layer III of dorsolateral prefrontal cortex (DLPFC) in mice. Control=control group; $\mathrm{Pb}=$ Lead acetate treated group; $V x=V i t e x i n$ treated group; and $\mathrm{Pb}+\mathrm{Vx}=$ Lead acetate and $\mathrm{Vi}$ texin treated group.

comparisons were made between the groups (Figure 7). In addition to the result seen, the neuronal length in control, Vitexin, and $\mathrm{Pb}+$ Vitexin groups was not statistically different $(\mathrm{p}$ $>0.05$ ) when compared with the $\mathrm{Pb}$ group. However, neuronal length in $\mathrm{Pb}+$ Vitexin group was significantly smaller $(\mathrm{p}<0.01)$ when compared with the Vitexin group. The cross-sectional area of neurons (Figure 8) were not statistically different ( $\mathrm{p}$ $>0.05$ ) between the groups but still appear lowest in $\mathrm{Pb}$ group when compared with either Vitexin or $\mathrm{Pb}+\mathrm{Vitexin}$ groups.

In Table 1, the thickness of layer II-III of DLPFC was significantly small in $\mathrm{Pb}$ group when compared with that in the control, Vitexin, and $\mathrm{Pb}+$ Vitexin group. Similarly, the thickness of layer II-III of DLPFC in the Pb+Vitexin group was significantly small when compared with that in either the control or the Vitexin group.

\section{Discussion}

This study shows that animals in $\mathrm{Pb}$-treated group took longer time to locate the dark box when compared with the group that had concurrent treatment of $\mathrm{Pb}+$ Vitexin (Figure 1). The result also shows that animals in Pb-treated group visited more incorrect holes before locating the dark box (Figure 2). This result indicates that $\mathrm{Pb}$ treatment may have affected the ability of the animals to learn or remember the location of the dark box earlier than expected after several trial period. This finding supported several earlier reports that implicated $\mathrm{Pb}$ 
exposure as an agent of cognitive impairment, particularly in a developing brain [13, 33-35]. This result further indicates that the treatment of Vitexin alongside $\mathrm{Pb}$ treatment will attenuate the possible cognitive impairment caused by $\mathrm{Pb}$. Earlier reports have indicated the various roles of Vitexin to improve cognitive impairment that was not caused by $\mathrm{Pb}$ exposure [36, 37]. According to Moosavirad et al., Pb-exposure cause reduction in the discrimination and object recognition index of learning tasks [38]. However, in this study, $\mathrm{Pb}$ treated group did not significantly show a reduction in preference for a new object when compared with $\mathrm{Pb}+$ Vitexin group (Figure 3 ). The differences observed could be as a result of differences in the duration of administration between the two studies.

The histoarchitectural observations in this study, shows that in groups that were treated with $\mathrm{Pb}$ only, degenerative changes that were characterized by numerous pyknotic neurons with fragmented cytoplasm and condensed nuclei were observed (Figure 4). Also lightly stained Nissl and numerous chromatolytic cells were observed. Several earlier studies had reported the ability of $\mathrm{Pb}$ to cause neuronal degeneration, chromatolysis and distortion of cortical layers [39-42]. This result indicates that the number of healthy neurons available to carry out normal function within the DLPFC will be low, thereby affecting is the function in working memory (Figure 1). In the group, where both $\mathrm{Pb}$ and Vitexin was concurrently administered, there was a significant improvement in a possible degenerative change and chromatolysis was significantly reduced (Figure 4). As part of previous studies, Vitexin has demonstrated its ability to decrease neuronal cell death $[43,44]$ through a different mechanism and to significantly improve neuronal cell structure and function $[24,45]$. This result in the $\mathrm{Pb}+$ Vitexin group, indicates that the number of healthy neurons in DLPFC will be more than the degenerated ones when compared to $\mathrm{Pb}$ group (as Figure 4,6). In this study, amyloid aggregation was not observed in any of the groups probably because of the dose and duration of treatment used or the type of microscope used to capture the stained sections (Figure 5).

This study shows that there was no significant difference in intercellular distance, neuronal length, and the cross-sectional area of neurons in $\mathrm{Pb}$ group when compared with the $\mathrm{Pb}+$ Vitexin group. This result indicates that regardless of $\mathrm{Pb}$ only treatment or $\mathrm{Pb}+$ Vitexin treatment, the intercellular distance, neuronal length and the cross-sectional area of neurons remain the same. Furthermore, the thickness of layer II-III of DLPFC was significantly small when compared with the $\mathrm{Pb}+$ Vitexin group. According to an earlier report by Defelipe et al., layer $2 / 3$ of mouse cortical thickness was $1210 \mu \mathrm{m}$ [46]. The result of this study indicates that the number of components of layer II-III of DLPFC in Pb group would be smaller than $\mathrm{Pb}+$ Vitexin group.

\section{Conclusion}

The result of this study has shown that concurrent administration of Vitexin and $\mathrm{Pb}$ will significantly reduce neurodegeneration and improve working memory. However, $\mathrm{Pb}$ treatment or both $\mathrm{Pb}$ and Vitexin treatment does not have an effect on intercellular distance, neuronal length and cross-sectional area of neurons in layer III of DLPFC.

\section{Acknowledgements}

The authors thank Mr Leviticus Arietarhire and Dr Emeka at central research and diagnostic laboratory, Ilorin.

\section{Conflict of interest}

Authors declare no conflicts of interest.

Funding: This research did not receive any specific grant from funding agencies in the public, commercial, or not-forprofit sectors.

\section{References}

1. Chauhan NB, Mehla J. Chapter 27 - Ameliorative effects of nutraceuticals in neurological disorders. Bioactive nutraceuticals and dietary supplements in neurological and brain disease Academic Press: San Diego. 2015, p. 245-260.

2. Lương VQK, Nguyễn LTH. Chapter 28 - The role of Caffeine in neurodegenerative diseases: possible genetic and cellular signaling mechanisms. Bioactive nutraceuticals and dietary supplements in neurological and brain disease. Academic Press: San Diego.2015, p. 261-279.

3. Rauh VA, Margolis AE. Research review: environmental exposures, neurodevelopment, and child mental health - new paradigms for the study of brain and behavioral effects. J Child Psychol Psychiatry 2016; 57(7): 775-793.

4. Orisakwe OE. The role of lead and cadmium in psychiatry. $\mathrm{N} \mathrm{Am} \mathrm{J}$ Med Sci 2014; 6(8): 370-376.

5. Tran NQV, Miyake K. Neurodevelopmental disorders and environmental toxicants: epigenetics as an underlying mechanism. Int J Genomics. 2017; 7526592.

6. Stackelberg K, Guzy E, Chu T, Claus HB. Exposure to mixtures of metals and neurodevelopmental outcomes: a multidisciplinary review using an adverse outcome pathway framework. Risk Anal 2015; 35(6): 971-1016.

7. Thangarajan S, Vedagirl A, Somasundaram S, Sakthimanogaran R, Murugessan M. Neuroprotective effect of morin on lead acetate- induced apoptosis by preventing cytochrome $\mathrm{c}$ translocation via regula- 
tion of Bax/Bcl-2 ratio. Neurotoxicol Teratol 2018; 66:35-45.

8. Sharma B, Singh S, Siddiqi NJ. Biomedical implications of heavy metals induced imbalances in redox systems. Biomed Res Int 2014; 640754.

9. Barkur RR, Bairy LK. Assessment of oxidative stress in hippocampus, cerebellum and frontal cortex in rat pups exposed to lead $(\mathrm{Pb})$ during specific periods of initial brain development. Biol Trace Elem Res 2015;164(2): 212-218.

10. Sharma P,Chambial S, Shukla KK. Lead and neurotoxicity. Indian J Clin Biochem 2015; 30(1): 1-2.

11. Ahmed MB, Ahmed MI, Meki AR, AbdRaboh N. Neurotoxic effect of lead on rats: relationship to apoptosis. Int J Health Sci (Qassim) 2013;7(2):192-199.

12. Mason LH, Harp JP, Han DY. Pb neurotoxicity: neuropsychological effects of lead toxicity. Biomed Res Int, 2014: 840547.

13. Zhang L, Tu R, Wang Y, Hu Y, Li X, Cheng X et al. Early-Life exposure to lead induces cognitive impairment in elder mice targeting SIRT1 phosphorylation and oxidative alterations. Front Physiol 2017; 8: 446.

14. Afifi AK, Bergman RA. Functional neuroanatomy: Text and Atlas, 2nd ed. McGraw-Hill Education; 2005

15. Funahashi S. Working memory in the prefrontal cortex. Brain Sci 2017; 7(5):49.

16. Kritzer MF, Goldman-Rakic PS. Intrinsic circuit organization of the major layers and sublayers of the dorsolateral prefrontal cortex in the rhesus monkey. J Comp Neurol 1995; 359(1): 131-143.

17. Petanjek Z, Sedmak D, Džaja D, Hladnik A, Rašin, MR, Jovanov-Milosevic $\mathrm{N}$. The protracted maturation of associative layer IIIC pyramidal neurons in the human prefrontal cortex during childhood: a major role in cognitive development and selective alteration in autism. Front Psychiatry 2019; 10:122.

18. Arnsten AF, Wang M. Targeting Prefrontal cortical systems for drug development: potential therapies for cognitive disorders. Annu Rev Pharmacol Toxicol 2016; 56:339-360.

19. Muralidhara KG. Chapter 29 - Dietary supplements as cognitive enhancers: the role of Flavonoid-rich foods and their relevance in agerelated neurodegeneration. Bioactive nutraceuticals and dietary supplements in neurological and brain disease. Academic Press: San Diego. 2015. p. 281-290.

20. Arredondo F, Echeverry C, Blasina F, Cassanello LV, Diaz M, Rivera F et al. Chapter 25 - Flavones and Flavonols in brain and disease: facts and pitfalls. Bioactive nutraceuticals and dietary supplements in neurological and brain disease. Academic Press: San Diego. 2015. p. 229236.

21. He M, Min JW, Kong WL, He XH, Li JX, Peng BW. A review on the pharmacological effects of vitexin and isovitexin. Fitoterapia 2016;115:74-85

22. Choi JS, Islam MN, Ali MY, Kim EJ, Kim YM, Jung HA. Effects of C-glycosylation on anti-diabetic, anti-Alzheimer's disease and anti-inflammatory potential of apigenin. Food Chem Toxicol 2014;64:27-33.

23. Hritcu L, Ionita R, Postu PA, Gupta GK, Turkez H, Lima TC et al. Antidepressant Flavonoids and their relationship with oxidative stress. Oxid Med Cell Longev 2017; 5762172.

24. Lima LKF, Pereira SKS, Junior ROSS, Santos FPDS, Nascimento ADS, Feitosa CM et al. A brief review on the neuroprotective mechanisms of Vitexin. Biomed Res Int 2018; 4785089.
25. Nabavi SF, Khan H, D'onofrio G, Šamec D, Shirooie S, Dehpour AR. Apigenin as neuroprotective agent: of mice and men. Pharmacol Res 2018;128:359-365.

26. Rosa SI, Rios-Santos F, Balogun SO, Martins DT. Vitexin reduces neutrophil migration to inflammatory focus by down-regulating pro-inflammatory mediators via inhibition of p38, ERK1/2 and JNK pathway. Phytomedicine 2016; 23(1):9-17.

27. Yang L, Yang ZM, Zhang N, Tian Z, Liu SB, Zhao MG. Neuroprotective effects of vitexin by inhibition of NMDA receptors in primary cultures of mouse cerebral cortical neurons. Mol Cell Biochem 2014; 386(12):251-258.

28. Zhu Q, Mao LN, Liu CP, Sun YH, Jiang B, Zhang W et al. Antinociceptive effects of vitexin in a mouse model of postoperative pain. Sci Rep 2016; 6:19266

29. Rosenfeld CS, Ferguson SA. Barnes maze testing strategies with small and large rodent models. J Vis Exp 2014;(84): e51194.

30. Huang TN, Hsueh YP. Novel object recognition for studying memory in mice. Bio-protocol 2014;4(19):e1249.

31. Bancroft JD, Gamble M. Theory and practice of histological techniques. 6th ed. London: Churchill Livingstone. 2008

32. Werd HJ, Uylings HB. Comparison of (stereotactic) parcellations in mouse prefrontal cortex. Brain Struct Funct 2014;219(2):433-459.

33. Driscoll LL, Strupp BJ. Assessment of attention and inhibitory control in rodent developmental neurotoxicity studies. Neurotoxicol Teratol 2015; 52(Pt A):78-87.

34. Sprowles JLN, Amos-Kroohs RM, Braun AA, Sugimoto C, Vorhees CV, Willams MT. Developmental manganese, lead, and barren cage exposure have adverse long-term neurocognitive, behavioral and monoamine effects in Sprague-Dawley rats. Neurotoxicol Teratol 2018; 67:50-64.

35. Chen F, Zhou CC, Yang Y, Liu JW, Yan CH. GM1 Ameliorates lead-induced cognitive deficits and brain damage through activating the SIRT1/CREB/BDNF pathway in the developing male rat hippocampus. Biol Trace Elem Res 2019;190(2):425-436.

36. Nurdiana S, Goh YM, Hafandi A, Dom SM, Nur Syimal'ain A, Noor Syaffinaz NM et al. Improvement of spatial learning and memory, cortical gyrification patterns and brain oxidative stress markers in diabetic rats treated with Ficus deltoidea leaf extract and vitexin. J Tradit Complement Med 2018; 8(1):190-202.

37. Oliveira DR, Zamberiam CR, Gaiardo RB, Rêgo GM, Cerutti JM, Cavalheiro AJ et al. Flavones from Erythrina falcata are modulators of fear memory. BMC Complement Altern Med 2014; 14:288.

38. Moosavirad SA, Rabbani M, Sharifzadeh M, Hoaawini-Sharifabad A. Protective effect of vitamin C, vitamin B12 and omega-3 on lead-induced memory impairment in rat. Res Pharm Sci 2016;11(5):390-396.

39. Mahmoud YI, Sayed SS. Effects of L-cysteine on lead acetate induced neurotoxicity in albino mice. Biotech Histochem 2016; 91(5):327-332.

40. Adedayo AD, Stephen AO, Adekilekun TA, Daniel AT. Lead induces inflammation and neurodegenerative changes in the rat medial prefrontal cortex. Anatomy 2017;11(2):79-86.

41. Highab SM, Magaji RA, Muhammad BY. Effect of Lead poisoning and antidepressant drug on the cerebral cortex of the Wistar rats. Acta Scientific Pharmaceutical Sciences 2018; 2(5):16-21.

42. Deveci E. Ultrastructural effects of lead acetate on brain of rats. Toxicol Ind Health 2006; 22(10):419-422. 
43. Min JW, Hu JJ, He M, Sanchez RM, Huang WX, Liu YQ et al. Vitexin reduces hypoxia-ischemia neonatal brain injury by the inhibition of HIF-1alpha in a rat pup model. Neuropharmacology, 2015. 99: p. 3850.

44. Wang Y, Zhen Y, Wu X, Jiang Q, Li X, Chen Z et al. Vitexin protects brain against ischemia/reperfusion injury via modulating mitogenactivated protein kinase and apoptosis signaling in mice. Phytomedi- cine 2015; 22(3):379-384.

45. An F, Yang G, Tian J, Wang S. Antioxidant effects of the orientin and vitexin in Trollius chinensis Bunge in D-galactose-aged mice. Neural Regen Res 2012;7(33): 2565-2575.

46. Defelipe J. The evolution of the brain, the human nature of cortical circuits, and intellectual creativity. Front Neuroanat 2011; 5: 29. 